\title{
Digital Fetal Scalp Stimulation
}

National Cancer Institute

\section{Source}

National Cancer Institute. Digital Fetal Scalp Stimulation. NCI Thesaurus. Code C114087.

A fetal stimulation technique that uses transvaginal digital pressure or rubbing to the fetal head to elicit a fetal heart rate acceleration response during labor. 